\title{
Gonococcal Ophthalmia Neonatorum
}

National Cancer Institute

\section{Source}

National Cancer Institute. Gonococcal Ophthalmia Neonatorum. NCI Thesaurus. Code C116816.

Inflammation of the conjunctiva in a newborn due to Neisseria gonorrhoeae which was acquired during labor and delivery. 